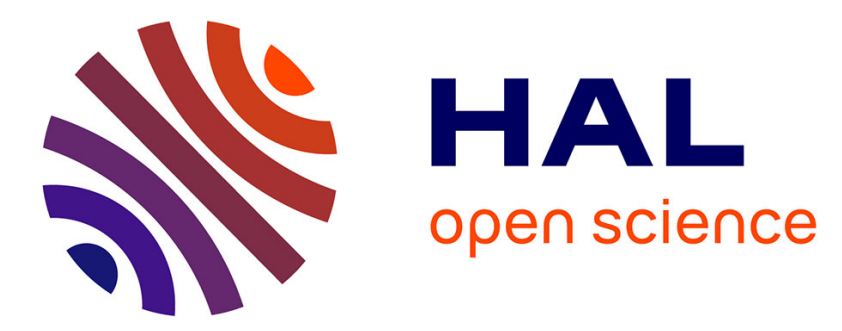

\title{
High temperature gradient calorimetric wall shear stress micro-sensor for flow separation detection
}

Cécile Ghouila-Houri, Quentin Gallas, Eric Garnier, Alain Merlen, Romain

Viard, Abdelkrim Talbi, Philippe Pernod

\section{> To cite this version:}

Cécile Ghouila-Houri, Quentin Gallas, Eric Garnier, Alain Merlen, Romain Viard, et al.. High temperature gradient calorimetric wall shear stress micro-sensor for flow separation detection. Sensors and Actuators A: Physical , 2017, 266, pp.232-241. 10.1016/j.sna.2017.09.030 . hal-01705613

\section{HAL Id: hal-01705613 \\ https://hal.science/hal-01705613}

Submitted on 9 Feb 2018

HAL is a multi-disciplinary open access archive for the deposit and dissemination of scientific research documents, whether they are published or not. The documents may come from teaching and research institutions in France or abroad, or from public or private research centers.
L'archive ouverte pluridisciplinaire HAL, est destinée au dépôt et à la diffusion de documents scientifiques de niveau recherche, publiés ou non, émanant des établissements d'enseignement et de recherche français ou étrangers, des laboratoires publics ou privés. 


\title{
High temperature gradient calorimeter wall shear stress micro-sensor for flow separation detection
}

\author{
Cécile Ghouila-Houri $^{(1,2, *)}$, Quentin Gallas ${ }^{(2)}$, Eric Garnier ${ }^{(2)}$, Alain Merlen ${ }^{(1,2)}$, Romain Viard ${ }^{(3)}$, Abdelkrim Talbi \\ (1), Philippe Pernod ${ }^{(1)}$ \\ (1) Univ. Lille, CNRS, Centrale Lille, ISEN, Univ. Valenciennes, UMR 8520-IEMN, LIA LICS/LEMAC, F-59000 Lille, France \\ (2) ONERA, Chemin de la Hunière 91123 Palaiseau, France \\ (3) Fluiditech, Thurmelec, 68840 Pulversheim, France \\ (*) Corresponding author email: cecile.ghouila@onera.fr
}

\begin{abstract}
The paper describes and discusses the design and testing of an efficient and high-sensitive calorimetric thermal sensor to measure simultaneously the magnitude and the direction of wall shear stress in aerodynamic flows. The main technical application targeted is the back flow and the flow separation detection for active flow control. The measurement principle is based on the flow-induced forced heat convection transfer on a heater element. The sensor is micro-structured with three parallel substrate-free wires presenting a high aspect ratio and supported by periodic perpendicular $\mathrm{SiO}_{2}$ micro-bridges ensuring a mechanical toughness and a thermal insulation relatively to the bulk substrate with high thermal inertia. The central wire is made of a multilayer structure (Au/TiSiO2/Ni/Pt/Ni/Pt/Ni/SiO 2 ) and is composed of a heater element $(\mathrm{Au} / \mathrm{Ti})$ and a thermistor $(\mathrm{Ni} / \mathrm{Pt} / \mathrm{Ni} / \mathrm{Pt} / \mathrm{Ni})$ enabling to measure the heater temperature. The upstream and downstream wires are thermistors enabling to operate in the calorimetric mode. This design provides a high temperature gradient and a homogeneous temperature distribution along the wires. The sensor operates in both constant current mode and constant temperature mode, with a feedback on current enabled by uncoupling heating and measure. Welded on a flexible printed circuit, the sensor was flush mounted on the wall of a turbulent boundary layer wind tunnel. The experiments, conducted in both attached and separated flow configurations, demonstrate the sensor sensitivity to the wall shear stress up to $2.4 \mathrm{~Pa}$ and the ability of the sensor to perform flow direction sensing for back-flow detection in a separated flow configuration.
\end{abstract}

Keywords

MEMS sensors; Wall shear-stress sensor; Flow separation detection; Flow control

\section{Introduction}

Active flow control systems are developed to promote air safety, reduce energetic consumption or increase airplanes efficiency. A potential good candidate for applying flow control strategy is flow separation which is mostly unwanted for many applications and even dangerous in aviation. It is an unstable flow that can increase drag and energy losses, and decrease lift. The measurement of wall shear stress is thereby needed for a better location of this effect for implementing a control strategy ([1], [2]).

For Newtonian fluid like air, the shear stress $\tau$ on a solid surface is given by Equation (1):

$$
\tau=\mu \cdot(\partial u / \partial y)_{w a l l}
$$

where $\mu$ is the air dynamic viscosity, $u$ the flow velocity parallel to the wall, and $y$ the axis normal to the wall as defined on Figure 1 (a).

Figure 1 illustrates two main kinds of flow separation: the boundary layer separation due to an adverse pressure gradient occurring on a surface with no sharp edges in (a), and another one due to a geometrical obstacle (cavity, obstacle, sharp edges...) in (b). 


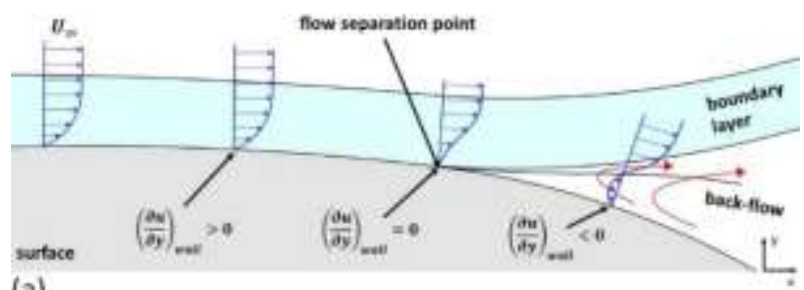

(a)

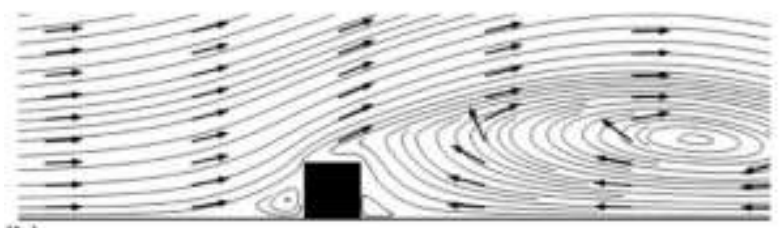

(b)

\section{Figure 1: (a) Schematic of a flow separation on an airfoil like surface (b) A geometry-based separation}

On an airfoil-like surface like in Figure 1 (a), it is known that an adverse pressure gradient can produce a separation of the boundary layer by stiffening the velocity profile and consequently decreasing the friction, before the separation, and creating a back-flow in a separation bubble. In the case (b) the flow separation due to a geometrical obstacle that leads by construction to a separation bubble [3]. As shown on Figure 1 and according to Equation (1), the wall shear stress, and particularly its orientation, is directly linked with the flow separation phenomena and its measurement is a key point to detect the state of the flow, either attached or separated.

When measuring fluctuation quantities in high Reynolds number turbulent boundary layers, wall shear stress sensors have to resolve both small length- and velocity-scales at high frequencies, in the view of Kolmogorov scales [4]. Therefore the need of very small, fast and high sensitive measurement devices can be fulfilled by Micro-ElectroMechanical Systems (MEMS) technology [5]. Although the present paper does not tackle the fluctuations issue, it must be underlined that the technology presented here will be, in a short future, a good candidate for unsteady measurement at such small scales.

Micro-machined flow sensors can be divided into two groups, based on different measurement methods: 'direct' measurement or 'indirect' measurement [6]. For direct measurement of wall shear stress, sensors usually use a floating element that is displaced laterally by the tangential viscous forces in the flow. This displacement implies a variation of an electrical parameter. For instance, in [7] the authors developed a capacitive wall-shear stress sensor with the floating element displacement implying a capacitive variation, reflected in an electric potential variation; the authors in [8] simulated a cantilever-based flow sensor using the piezoresistance effect; and authors in [9] designed and manufactured capacitive airflow sensors based on out-of-plane cantilevers. These sensors present the clear advantage of a direct wall shear stress measurement. However the necessary floating element implies an electro-mechanical coupling which is sensitive to vibrations. With miniaturization, the mechanical resonance frequency comes close to the vibrations of the measured system structure, in case of moving structures like vehicles. Vibrations affect at least the measure but can also affect the sensor integrity. For avoiding these drawback indirect wall shear stress measurements were developed with various methods. For example, micro-fences using a cantilever structure and piezoresistors are presented in [10]; the exploitation of optical resonances such as whispering gallery modes of dielectric microspheres is proposed in [11] (for which the optical resonance shifts with radial deformations of the spheres due to the shear stress); the deflection of micro-pillars is presented in [12] and thermal-based sensors are presented in the next paragraphs of the present paper. The physical principle used in these latter consists in taking advantage of the convective heat transfer between an electrically heated resistor and a surrounding cooler fluid [6]. As they do not involve a mechanical moving part, thermal flow sensors are widely adopted when dealing with fluid dynamics including laminar or turbulent flows.

Two main kinds of thermal sensors for velocity and wall shear stress have been developed over the years: hotwires sensors and hot-film sensors. The difference between them lies in the designed structure: in hot-wire sensors the metallic wire resistor is free from the substrate, fixed by two prongs and placed within the flow. On the other side, the metallic wire of hot-film sensors is deposited on a substrate and placed on a surface adjacent to the flow. Hot-wire sensors are mainly free from the substrate which enable an optimal heating uniformity and high sensitivity ([13]-[15]) but they are fragile and 3D thermal effects occur at the ends of the wire. On the contrary, hot-film sensors are very robust in front of their operational constrains. However, they suffer from heat losses through the substrate on which the metallic wire is deposited. Various materials have thus been used to increased thermal insulation such as silicon 
nitride [16], glass [17] or flexible polymer ([18], [19],[20]). These sensors, easy to mount flush to the wall, are often used for detecting flow separations and for wall shear stress measurement. To improve the performances (sensitivity and time response) of hot-films sensors, the heat losses need to be reduced and using bulk-machining techniques, the metallic wire might be deposited on a membrane separated from the substrate by a cavity underneath [21].

This paper presents a thermal wall shear stress sensor elaborated for taking advantages of both hot-film sensors and hot-wire sensors. In the designed structure, the heater and the measurement elements consist of long metallic wires free from the substrate and suspended by periodic silicon oxide micro-bridges [22]. This design allows an efficient thermal insulation and simultaneously mechanical toughness. The first results on this structure were presented in [23] with integration in a micro-channel. Then, an improved design added the measurement of the flow direction parameter ([24], [25]), using the calorimetric principle. The present paper deals with the same kind of sensor initiated in [25], but targeting more specifically on the separation detection for flow control applications. Are presented here all the characterizations performed on the sensor, electrical and thermal, with comparisons to numerical studies, and wind tunnel experiments in both attached and separated flows configurations.

\section{The thermal MEMS sensor: design and fabrication process}

\subsection{Design and working principle}

The sensitive part of the sensor, presented in Figure 2, consists in three parallel micro-wires, free from the substrate, mechanically supported by silicon oxide micro-bridges over a cavity and designed to be set perpendicular to the flow. The central wire combines heating and wall shear stress measurement as a classical hot-wire. The two other wires, arranged on both sides of the central wire, use the calorimetric principle and are used to detect the flow direction. As they are cooled differently by the flow, the upstream wire being cooler than the downstream one, the temperature difference between them indicates the flow direction.

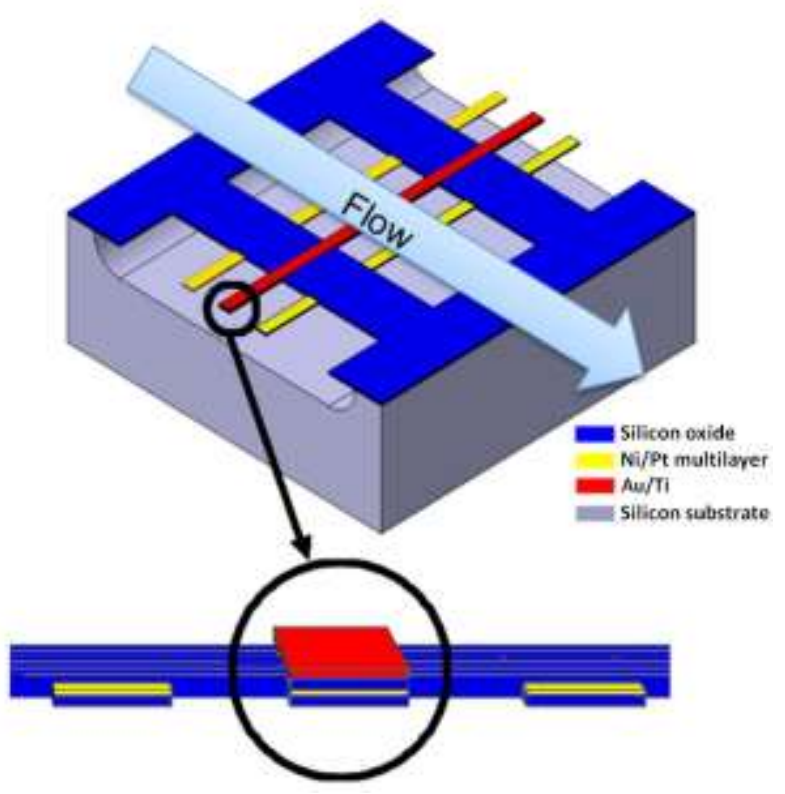

Figure 2: Schematic of the sensor design

The geometrical parameters are summarized in Table 1. Each wire is separated from the substrate to avoid heat losses by solid conduction into the substrate and to increase the flow induced convective heat transfer. The high aspect ratio of the heater enables a high temperature gradient in the flow direction and a homogeneous temperature profile along the wire. The oxide silicon bridges allow the structure to be mechanically resistant over the flow despite the length of the wires. The central wire is multilayer-structured: one layer is the heater, made of $\mathrm{Au} / \mathrm{Ti}$, the second one is the measurement wire, a Ni/Pt multilayer, and a third one of $\mathrm{SiO} 2$ separates the first two layers, acting as insulator. The heater layer is the only one powered, and it heats the whole sensor structure. The all three other Ni/Pt layers are designed for sensing: there are only crossed by a $100 \mu \mathrm{A}$ current for measurement using the 4-points measurement technique. 
Measure and heating are thereby electrically uncoupled to improve the signal to noise ratio and to allow the choice in materials. Therefore, the measurement wires are $\mathrm{Ni} / \mathrm{Pt} / \mathrm{Ni} / \mathrm{Pt} / \mathrm{Ni}$ multilayers reaching about $130 \mathrm{~nm}$ height in total. This material was chosen for its temperature-dependent resistivity, as it will be shown on paragraph 3 . The heater is mainly made of $\mathrm{Au}(200 \mathrm{~nm})$, a material more stable to temperature. The Ti layer of $20 \mathrm{~nm}$ is an adhesion layer. The measurement is based on the 4-points technique: the measurement wires are crossed by a $100 \mu \mathrm{A}$ current enabling the resistance measurement without heating the wires.

\begin{tabular}{|l|l|l|l|}
\hline Parameters & Sensing wires & Heater & Brides \\
\hline Length & $1 \mathrm{~mm}$ & $1 \mathrm{~mm}$ & $30 \mu \mathrm{m}$ \\
Width & $3 \mu \mathrm{m}$ & $3 \mu \mathrm{m}$ & $7 \mu \mathrm{m}$ \\
Thickness & $130 \mathrm{~nm}$ & $220 \mathrm{~nm}$ & $500 \mathrm{~nm}$ \\
Cavity depth & $20 \mu \mathrm{m}$ & & \\
Number & 3 & 1 & 33 \\
\hline
\end{tabular}

Table 1: Geometrical parameters of the sensor

Finite element simulation was performed using COMSOL Multiphysics to study the sensor working behaviour. As seen on Figures 3 (a), (b) and (c), when the gold resistor is heated by an electric current, the heat is transferred to the measurement wires and the surrounding fluid by conduction. Figures 3 (a) and (b) present the heat distribution in the sensor structure (wires and bridges) and the fluid for a $10 \mathrm{~mW}$ heating power. With a low power consumption, an increase of about $90 \mathrm{~K}$ is reached with flow at rest.

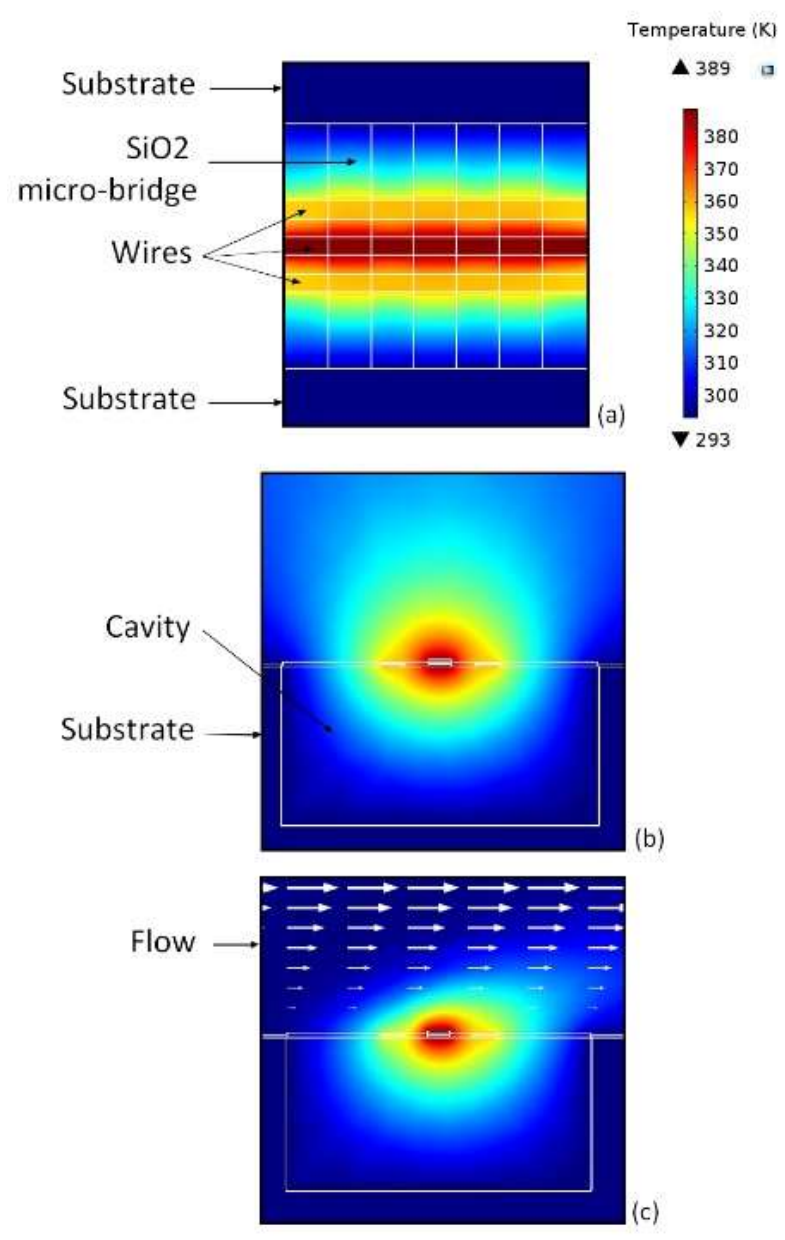

Figure 3: COMSOL Finite element simulations - $10 \mathrm{~mW}:($ a) heat distribution in the wires plane with flow at rest, (b) heat distribution in the plane perpendicular to wires with flow at rest, (c) heat distribution in the plane perpendicular to wires for $10 \mathrm{~mW}$ and flow at $20 \mathrm{~m} / \mathrm{s}$

In Figure 3 (c), the flow velocity cools the structure by forced convection leading to a temperature decrease, and the thermal boundary layer is deformed. Here, the boundary layer flow was modelled using Equation 2, valid because the velocity field is modelled in the linear sublayer region of a boundary layer.

$$
u=y \cdot(\tau / \mu)
$$




\subsection{Micro-fabrication and packaging on flexible printed circuit}

The micro-machining process was performed on a 3 inches (100) silicon wafer for the fabrication of more than a hundred sensors. The detailed process steps are presented in [25]. It contains six main steps and need four masks. Compared to [25], ], the layer thickness of $\mathrm{SiO}_{2}$ was decreased from $300 \mathrm{~nm}$ to $200 \mathrm{~nm}$, the Ni/Pt multilayer deposition was followed by a vacuum annealing to relax mechanical stress and improve stability, and the etch time to release the wire was increased resulting in a deeper cavity. All these modifications were made to perform a higher temperature elevation and provide a higher sensitivity.

Figure 4 (a) and (b) are Scanning Electron Microscopy (SEM) pictures of the manufactured micro-sensor. Figure 4 (a) displays the complete structure with the micro-bridges supporting the wires. Figure 4 (b) focuses on the central multi-layered structure (central wire) and allows to distinguish bright metal layers, which are respectively the heater on top and the measurement wire at the bottom, separated by a dark silicon oxide electrical insulator layer.

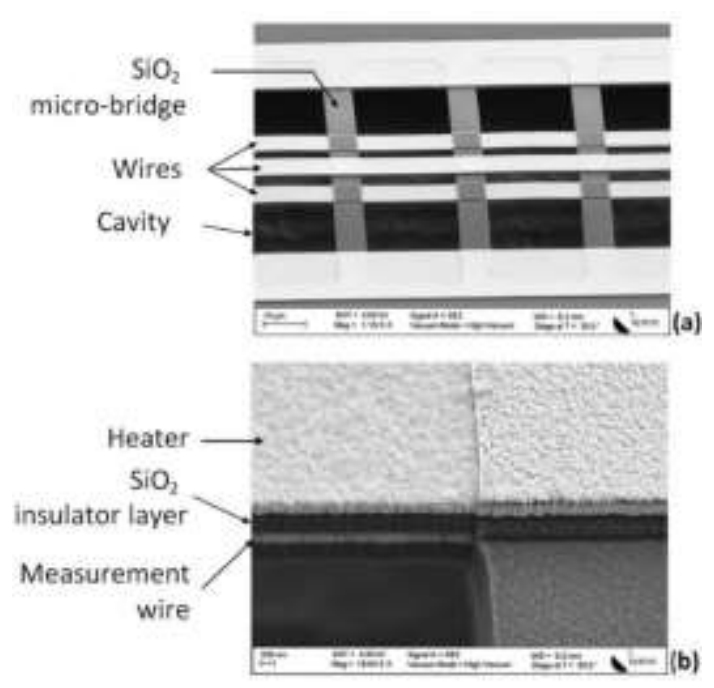

Figure 4: SEM pictures of the sensor: (a) global structure (b) central wire multilayer structure [24]

The final sensor chip is about $4 \mathrm{~mm}$ long by $3 \mathrm{~mm}$ wide, the main part of it being occupied by the large pads enabling the electrical contacts recovering at millimeter scale (Figure 5 (a)). The sensor was then welded on a flexible electronic printed circuit, as shown on Figure 5 (b), enabling it to adapt to a wind tunnel wall.
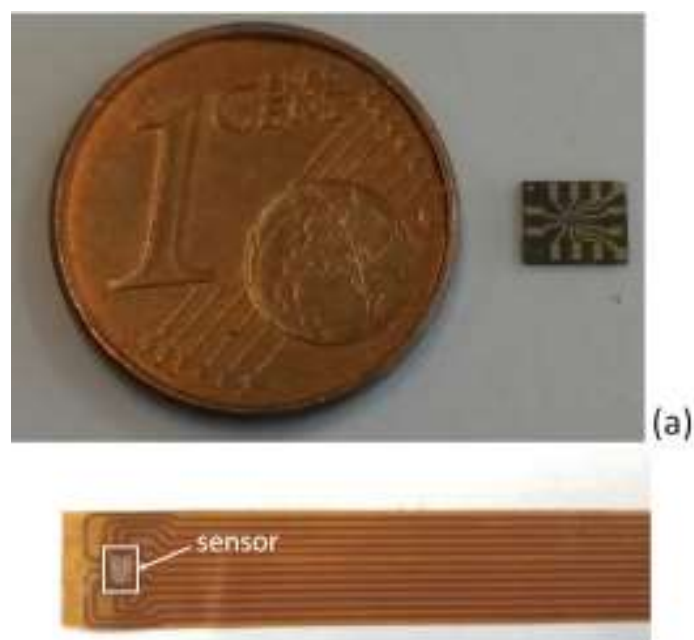

(b)

Figure 5: (a) Sensor chip compared to euro cent (b) Flexible packaging of the sensor

\section{Electrical and thermal response measurements}

The first set of measures were devoted to determinate the Temperature Coefficient of Resistance (TCR) and the temperature elevation with power. The TCR is a material characteristic and is defined by Equation (3): 


$$
T C R=\Delta R /\left(\Delta T \cdot R_{0}\right)
$$

where $R_{0}$ is the resistance of reference at $25^{\circ} \mathrm{C}, \Delta R$ the resistance variation and $\Delta T$ the temperature variation. The measured resistance variation with temperature (Fig. 6) exhibits a linear behaviour between $20^{\circ} \mathrm{C}$ and $70^{\circ} \mathrm{C}$ resulting in a TCR of about $2380 \pm 70 \mathrm{ppm} /{ }^{\circ} \mathrm{C}$, with a TCR dispersion measured along the 3 inches diameter wafer.

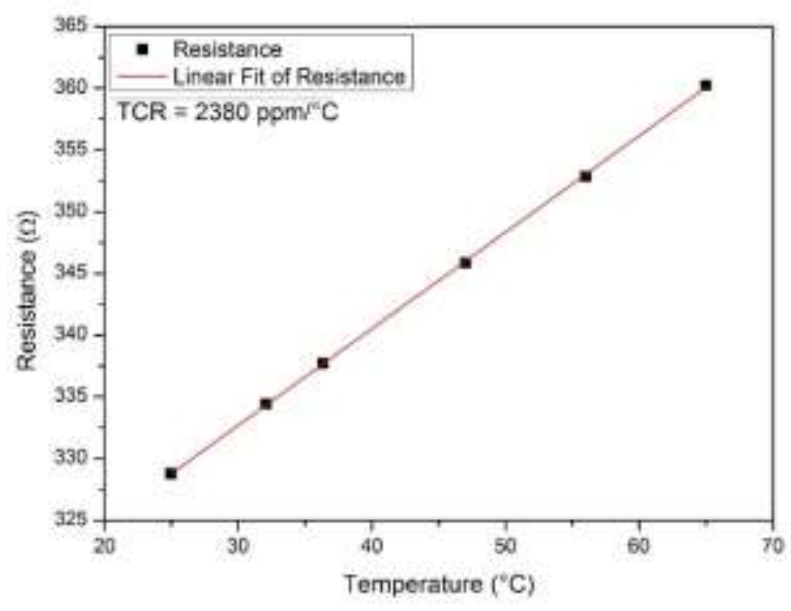

Figure 6: Pt/Ni/Pt multilayer resistance versus temperature

Afterwards, the temperature elevation by joule effect is determined. The measurement setup uses a Keithley 2400 source-meter. Experimental results without flow, compared to numerical ones, are presented on Figure 7. The numerical results are in agreement with the experimental data. Experimentally the temperature gradient reaches $9.1 \pm 0.3 \mathrm{~K} / \mathrm{mW}$ for the central measurement wire and $5.7 \pm 0.4 \mathrm{~K} / \mathrm{mW}$ for the lateral wires, with the dispersion measured across the wafer. The lateral wires are indeed distant from the heater with a $3 \mu \mathrm{m}$ air gap between them, whereas the central wire is only separated from the heater by $200 \mathrm{~nm}$ of silicon oxide, used for electrical insulation and not for thermal insulation.

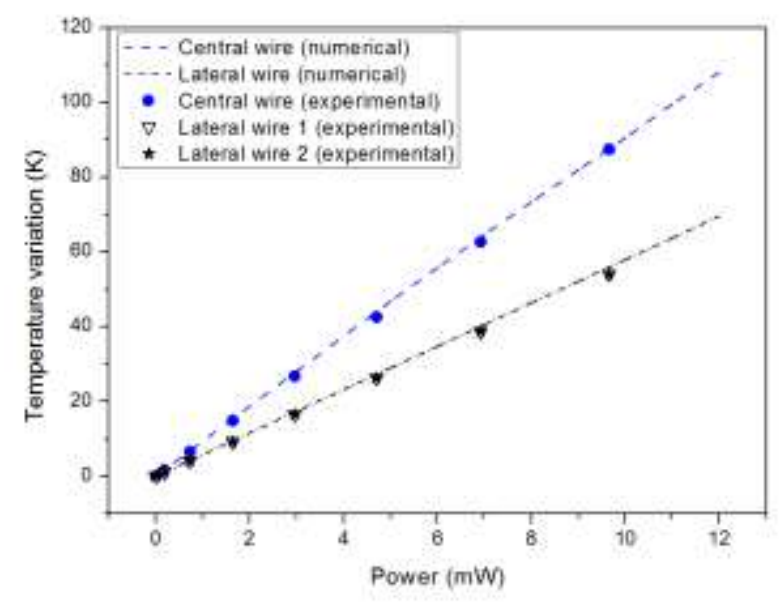

Figure 7: Electrical characterization (without flow) of the sensor for both central and lateral wires and comparison with numerical results

In order to ascertain the thermal behaviour of our device, a thermal imaging is performed using a thermal microscope equipped with an infrared camera (reference MWIR-512 from QFI, $12 \times$ Objective magnification corresponding to $2 \mu \mathrm{m} / \mathrm{pixel}$ ). Figure 8 (a) displays the temperature distribution of the heater and the surrounding surface when supplied by a power close to $7 \mathrm{~mW}$.

The micro-bridges structure allows a homogeneous temperature distribution along the wires and a high temperature gradient in the perpendicular direction. The heat distribution is compared to the numerical data on Figure 8 (b) which shows the result for the heat distribution perpendicular to the wires, at the location of a silicon oxide bridge. The experimental and numerical data were normalized by the maximum temperature. The experimental temperature profile is coherent with the simulation. 

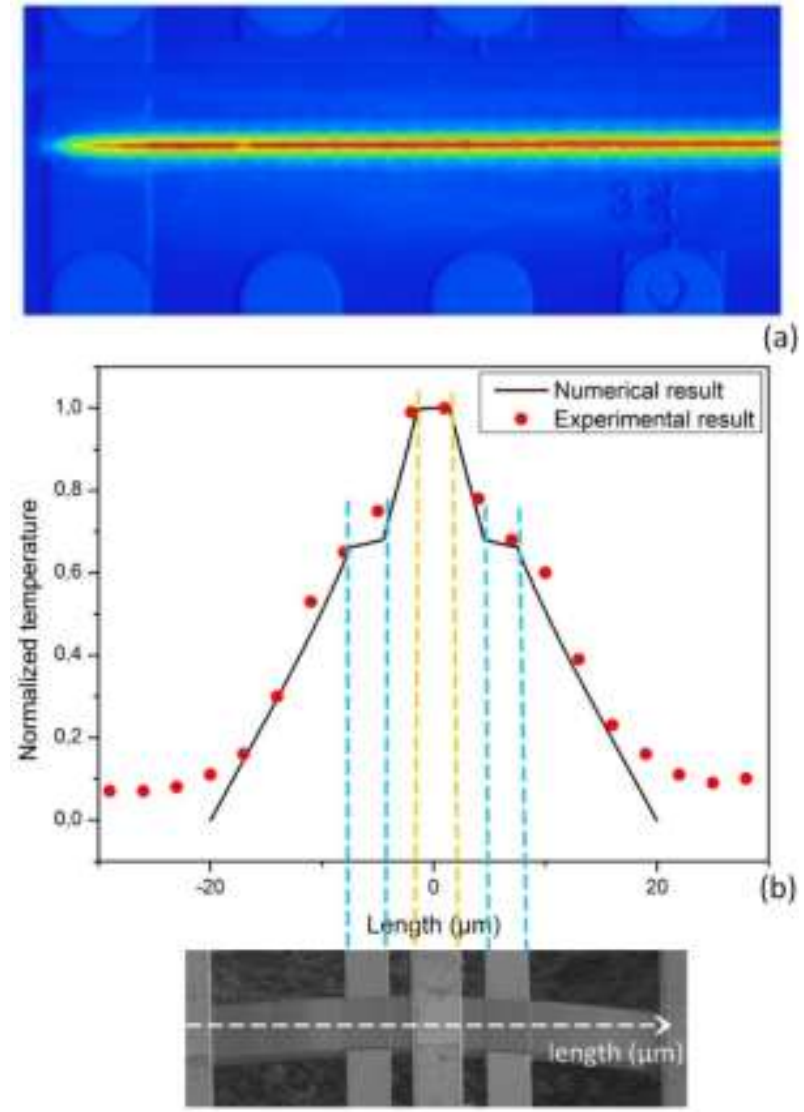

Figure 8: (a) Thermal camera picture along the length of the manufactured sensor heated with $6 \mathrm{~mA}$ current $(b)$ Temperature profile comparison between the experimental and numerical results, perpendicularly to the wires, at the location of a $\mathrm{SiO}_{2}$ bridge.

\section{Wind tunnel experiments for turbulent boundary layer}

\subsection{Experimental setup}

The shear stress measurement by the sensor was tested in a turbulent boundary layer during a wind tunnel experiment (Fig. 9 (a)). This $30 \mathrm{~cm} \times 30 \mathrm{~cm}$ test section wind tunnel operates with velocities from $10 \mathrm{~m} / \mathrm{s}$ to about $40 \mathrm{~m} / \mathrm{s}$. The flow velocity is measured by a Dantec hot-wire probe, referenced as 55P11, and placed at the center of the test section (15 cm away from the wall). The MEMS sensor is flush mounted at the wind tunnel wall (Fig. 9 (b)). A hot-film sensor (Dantec 55R47) is placed at the vicinity of the MEMS sensor, in the same cross section of the wind tunnel.
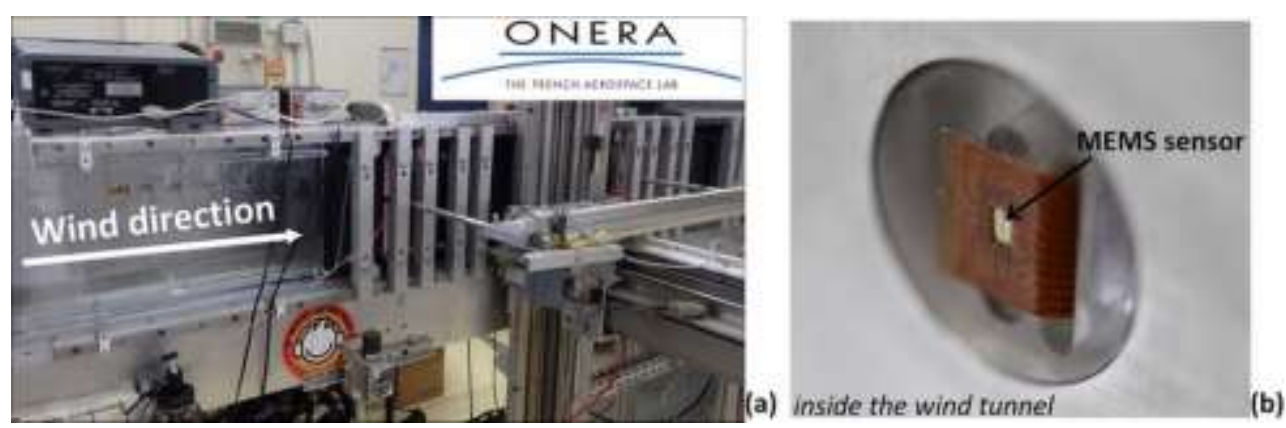

Figure 9: Turbulent boundary layer wind tunnel in ONERA Lille (b) Flush-mounted IEMN MEMS sensor in the wind tunnel wall 
The boundary layer in the wind tunnel was previously characterized with a conventional hot-wire probe mounted on a motorized system allowing displacements normal to the mean flow from the center of the wind tunnel to $0.3 \mathrm{~mm}$ close to the wall. The velocity profile of the boundary layer gave the experimental momentum thickness $\theta$ of the boundary layer at the MEMS sensor position in the wind tunnel and the corresponding skin friction coefficient $C_{f}$, using the relation of Coles-Fernholz developed in [26]:

$$
C_{f}=2 \cdot\left[\frac{1}{k} \cdot \ln \left(R e_{\theta}\right)+C\right]^{-2}
$$

with $k=0.384, C=4.127$ and $\operatorname{Re}_{\theta}=\left(\theta \cdot U_{\infty}\right) / v$, where $U_{\infty}$ is the flow velocity at the center of the wind tunnel and $v$, the cinematic viscosity. The wall shear stress is linked with the skin friction coefficient by Equation 5:

$$
\tau=\frac{1}{2} \cdot \rho \cdot U_{\infty}^{2} \cdot C_{f}
$$

with $\rho$ being the air density.

\subsection{Sensor response to wall shear stress variations}

In traditional thermal anemometry, three main operating modes exist: the 'constant current (CC) mode', the 'constant voltage (CV) mode' and the 'constant temperature (CT) mode'.

In Figure 10 (a), the sensor was used in CC mode with a $6 \mathrm{~mA}$ heating current, corresponding to about a power of $7 \mathrm{~mW}$. The results express the resistance variation $\Delta R$ in percent versus the wall shear stress given by equation (5) and the velocity profile measurements, for both the central and the lateral wires. $\Delta R$ is calculated by Equation (6):

$$
\Delta R(\%)=\frac{(R(7 m W, 0 P a)-R(7 m W, \tau))}{R(7 m W, 0 P a)}
$$
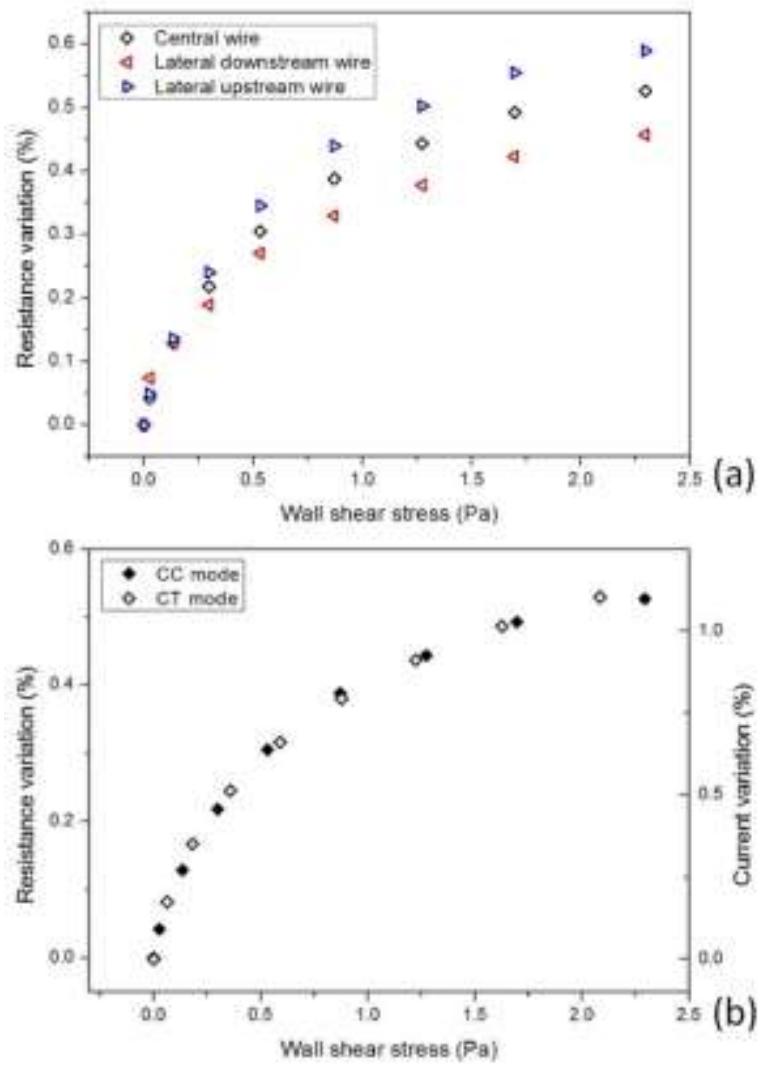

Figure 10: (a) Measured resistance variations versus wall shear stress for both the central and the lateral wires with the sensor operating in CC mode (b) Calibration comparison between CC and CT modes of operation

The results in Figure 10 (a) show the measured resistance variations for both the central wire and the lateral wires. As the wires are placed perpendicular to the flow, the lateral wires are distinguished as upstream and downstream the flow. The central wire presents up to $0.53 \%$ of resistance variation for $2.4 \mathrm{~Pa}$ while the upstream wire 
achieves $0.6 \%$ of variation for the same wall shear stress and the downstream wire, only $0.45 \%$. The lateral wires share the same electrical and thermal characteristics implying that the difference between their variations of resistances is induced by the flow. The wire upstream is indeed more cooled by the flow than the downstream one, implying that higher amplitude of resistance variation. The Figure 10 (b) presents a comparison between CC and CT modes, considering only the central wire maintained at about $65^{\circ} \mathrm{C}$ in $\mathrm{CT}$ mode. The sensor presents the same behaviour in both modes but it performs a higher response in CT mode with more than $1 \%$ of current variation for $2.4 \mathrm{~Pa}$.

The impact of the heating current on the sensor sensitivity is shown in Figure 12, for CC mode. As the heating current increased, the sensor sensitivity was improved. Therefore, depending on the aimed application, one can choose to decrease the heating current to save power: (i.e) for $4 \mathrm{~mA}$, the power consumed is close to $3 \mathrm{~mW}$ whereas for $6 \mathrm{~mA}$ the heating power is about $7 \mathrm{~mW}$ (cf. Figure 7).

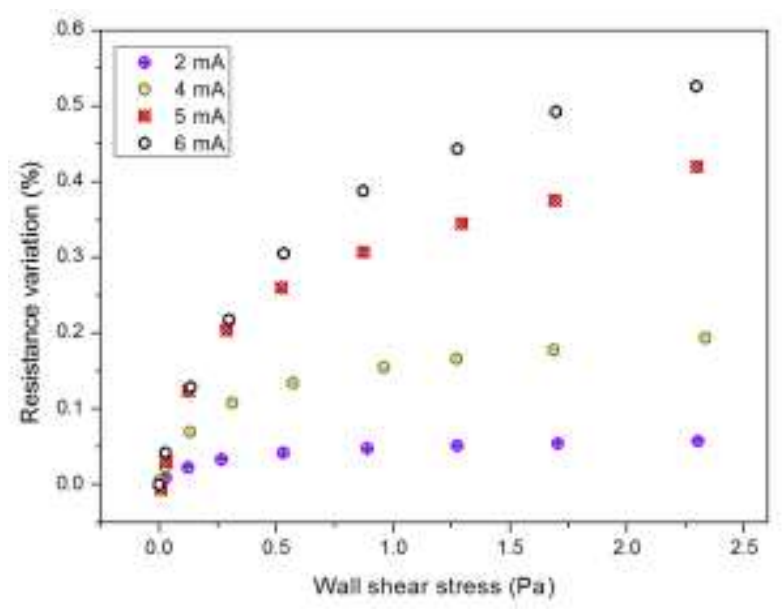

Figure 11: Measured resistance variations of the central wire versus wall shear stress for different heating currents - sensor used in CC mode

\subsection{Separated flow detection}

In [25], flow direction experiments were performed by changing the orientation of the sensor on its support. The results demonstrated the sensor ability to distinguish the flow direction in both senses, in attached flow situations. Here, the aim is to study the sensor capacity to detect separation and the induced back-flow. This was done by inserting, upstream of the sensor, a 2D step-like obstacle on the wind tunnel wall, as shown in Figure 12 (a) and (b).
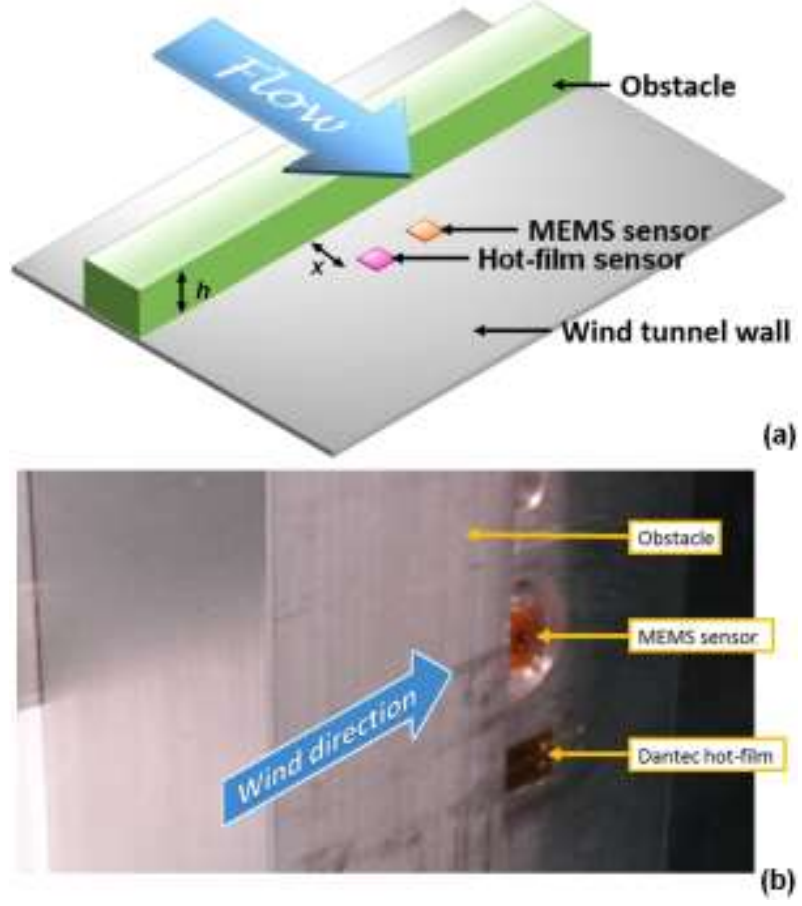

Figure 12: (a) Schematic of the obstacle experiment set up (b) Picture of set up in the wind tunnel 
Two different obstacles heights were considered with respectively $18 \mathrm{~mm}$ and $38 \mathrm{~mm}$ height. The sensor was flush mounted behind the obstacle, inside the recirculation region. The results are presented in Figures 13 and 14. The upstream flow velocity is taken at the entrance of the test section out of the boundary layer.
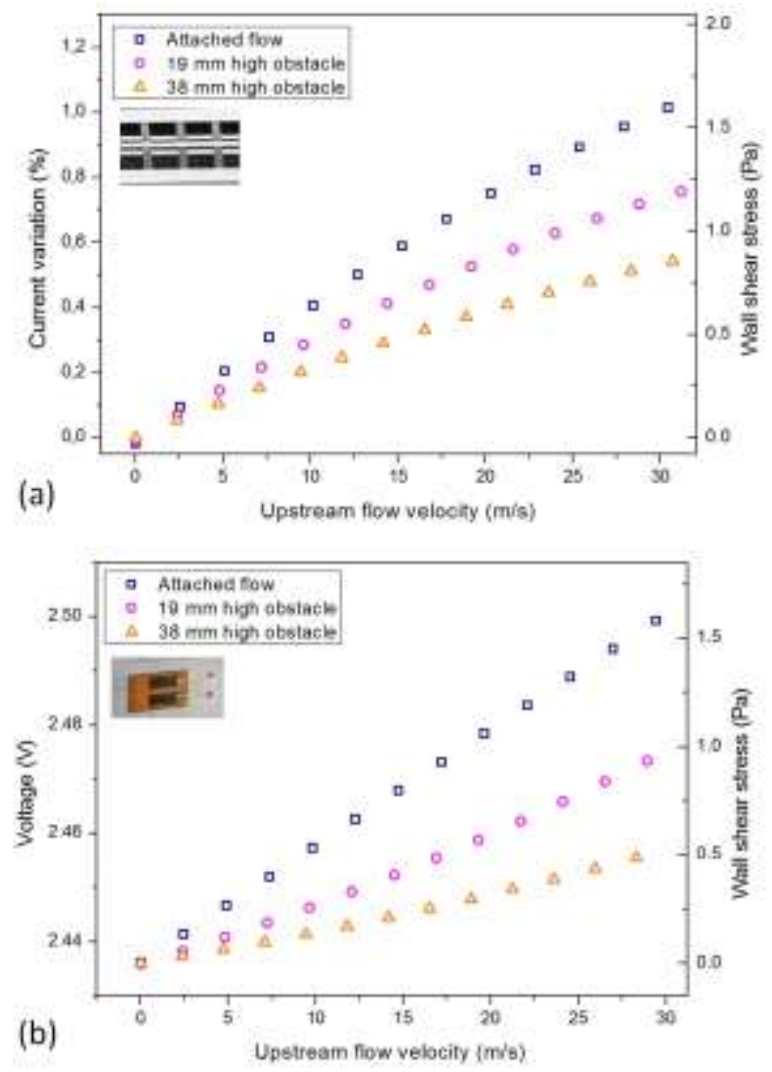

Figure 13: (a) Response of the sensor central wire in CT mode, in attached flow situation and separated flow situation with the two obstacles (b) Response of the Dantec hot-film sensor in the same situations

The behaviour of the MEMS central wire in attached and separated flow configurations is presented in Figure 13 (a), with the sensor used in CT mode $\left(65^{\circ} \mathrm{C}, 7 \mathrm{~mW}\right)$. Figure 13 (b) shows the response of the Dantec hot-film sensor (CT mode, $120{ }^{\circ} \mathrm{C}, 100 \mathrm{~mW}$ ) in the same situations.

On both results, the response is gradually less important consistently with the expected flow reversal attenuation when approaching the sensor toward the step from $x / h=2.3$ (for the $19 \mathrm{~mm}$ high obstacle) to $x / h=0.9$ (for the $38 \mathrm{~mm}$ high obstacle), as $x$ and $h$ defined on Figure 12. However, even if the global behaviour of the two sensors is similar, they do not measure the same wall shear stress, implying that they are not exposed to the same flow. Visualization techniques, like Particle Image Velocimetry, are needed to fully understand the measurements results.

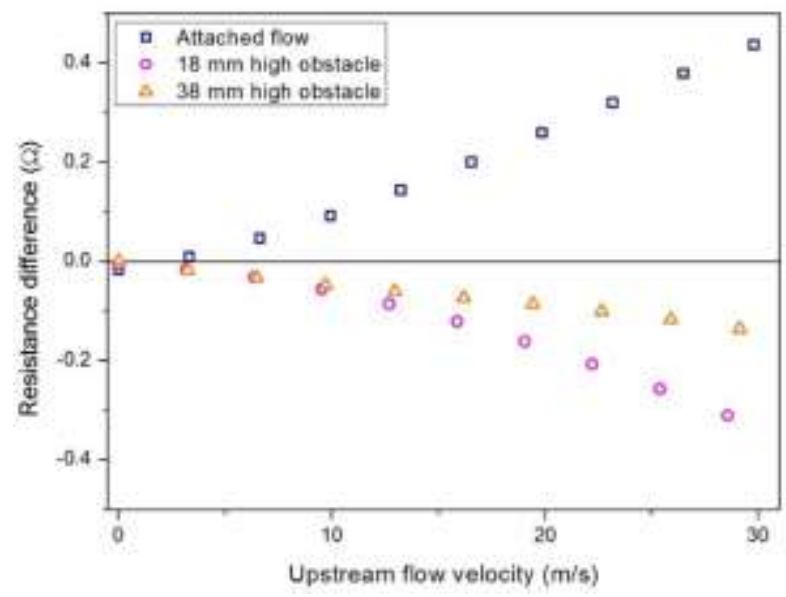




\section{Figure 14: Response of the lateral wires difference in attached flow situation and separated flow situation with the two obstacles (CT mode)}

Figure 14 presents the difference of resistance between the two lateral wires. It is clear that the sign changes between the attached and the detached flows. This demonstrates the sensor ability to provide simultaneously the modulus of the wall shear stress and its sign, enabling to detect recirculation bubbles due to separations.

\section{Conclusion}

Design, numerical simulations, fabrication, electro-thermal characterizations and wind tunnel experiments results of a novel hot-wire based wall shear stress sensor were presented in this paper. The design is a compromise between conventional hot-wires and hot-films sensors, taking advantages from both structures, as it consists in free hot-wires supported by silicon oxide micro-bridges. The sensor experiences a high temperature gradient, up to $9{ }^{\circ} \mathrm{C} / \mathrm{mW}$ and a high sensitivity to wall shear stress with up to $0.5 \%$ of resistance variation for $2.4 \mathrm{~Pa}$ in CC mode, and more than $1 \%$ of current variation in CT mode. It was also able to detect the sign of the stress due to its 3-wires based design. Experiments conducted in attached and separated flow situations demonstrated the capacity of the sensor to detect separation. In separated flow, the sensor detected the reduction of the wall shear stress modulus and its sign. Further characterizations will investigate the dynamical behaviour of the sensor for detecting shear stress fluctuations in unsteady flows. Then, further work, on a flap model similar to the one used in [2], will perform a flow control using the presented MEMS sensors in unsteady situation. This work will take advantage of this technology for open and closed-loop control strategies.

\section{Acknowledgments}

The French National Research Agency (ANR) in the framework of the ANR ASTRID "CAMELOTT" Project funded this work. It was supported by the regional platform CONTRAERO in the framework of the CPER ELSAT 2020 Project. The ELSAT 2020 project is co-financed by the European Union with the European Regional Development Fund, by the French State and the Hauts de France Region under the State Region Contracts (CPER). The authors also thank RENATECH, the French national nanofabrication network, and FEDER.

\section{References}

[1] Gad-el-Hak, 'Flow Control: The Future', J. Aircr., vol. 38, no. 3, pp. 402-418, 2001.

[2] T. Chabert, J. Dandois, and É. Garnier, 'Experimental closed-loop control of separated-flow over a plain flap using extremum seeking', Exp. Fluids, vol. 57, no. 3, Mar. 2016.

[3] H. Sturm, G. Dumstorff, P. Busche, D. Westermann, and W. Lang, 'Boundary Layer Separation and Reattachment Detection on Airfoils by Thermal Flow Sensors', Sensors, vol. 12, no. 11, pp. 14292-14306, Oct. 2012.

[4] V. Chandrasekaran, A. Cain, T. Nishida, L. N. Cattafesta, and M. Sheplak, 'Dynamic calibration technique for thermal shear-stress sensors with mean flow', Exp. Fluids, vol. 39, no. 1, pp. 56-65, Jul. 2005.

[5] L. Löfdahl and M. Gad-el-Hak, 'MEMS applications in turbulence and flow control', Prog. Aerosp. Sci., vol. 35, no. 2, pp. 101-203, Feb. 1999.

[6] L. Löfdahl and M. Gad-el-Hak, 'MEMS-based pressure and shear stress sensors for turbulent flows', Meas. Sci. Technol., vol. 10, no. 8, p. 665, 1999.

[7] V. Chandrasekharan, J. Sells, J. Meloy, D. P. Arnold, and M. Sheplak, 'A Microscale Differential Capacitive Direct Wall-Shear-Stress Sensor’, J. Microelectromechanical Syst., vol. 20, no. 3, pp. 622-635, Jun. 2011.

[8] P. Chen, Y. Zhao, and Y. Li, 'Fluid structure interaction analysis and simulation of micromachined cantileverbased flow sensor', in Nano/Micro Engineered and Molecular Systems (NEMS), 2014 9th IEEE International Conference on, 2014, pp. 350-353.

[9] N. André, B. Rue, G. Scheen, D. Flandre, L. A. Francis, and J.-P. Raskin, 'Out-of-plane MEMS-based mechanical airflow sensor co-integrated in SOI CMOS technology', Sens. Actuators Phys., vol. 206, pp. 67-74, Feb. 2014.

[10] T. von Papen, U. Buder, H. D. Ngo, and E. Obermeier, 'A second generation MEMS surface fence sensor for high resolution wall shear stress measurement', Sens. Actuators Phys., vol. 113, no. 2, pp. 151-155, Jul. 2004.

[11] T. Ioppolo, U. K. Ayaz, and M. V. Otugen, 'Performance of a micro-optical wall shear stress sensor based on whispering gallery mode resonators', in 47th AIAA Aerospace Sciences Meeting, 2009.

[12] S. Große and W. Schröder, 'Dynamic wall-shear stress measurements in turbulent pipe flow using the micropillar sensor MPS3', Int. J. Heat Fluid Flow, vol. 29, no. 3, pp. 830-840, Jun. 2008. 
[13] A. Talbi, L. Gimeno, J-C. Gerbedoen, R. Vard, A. Soltani, V. Mortet, V. Preobeazhensky, A. Merlen and P. Pernod, 'A micro-scale hot wire anemometer based on low stress (Ni/W) multi-layers deposited on nanocrystalline diamond for air flow sensing', J. Micromechanics Microengineering, vol. 25, no. 12, p. 125029, Dec. 2015.

[14] P. Pernod, L. Gimeno, A. Talbi, A. Merlen, R. Vard, V. Mortet, A. Soltani and V. Preobeazhensky, 'Hot-wire sensor of submillimeter size and associated method of production', FR2958754 (A1) 2011-10-14 WO2011128828 (A1) 2011-10-20 FR2958754 (B1) 2012-10-26 EP2561369 (A1) 2013-02-27 US2013125644 (A1) 2013-05-23 JP2013527436 (A) 2013-06-27 US8978462 (B2) 2015-03-17 EP2561369 (B1) 2015-04-01 DK2561369 (T3) 2015-07-06 JP5770828 (B2) 2015-08-26, 2011.

[15] Y. Fan, G. Arwatz, T. W. Van Buren, D. E. Hoffman, and M. Hultmark, 'Nanoscale sensing devices for turbulence measurements', Exp. Fluids, vol. 56, no. 7, Jul. 2015.

[16] E. Vereshchagina, R. M. Tiggelaar, R. G. P. Sanders, R. A. M. Wolters, and J. G. E. Gardeniers, 'Low power micro-calorimetric sensors for analysis of gaseous samples', Sens. Actuators B Chem., vol. 206, pp. 772-787, Jan. 2015.

[17] Y. Zhu, M. Qin, J. Huang, Z. Yi, and Q.-A. Huang, 'Sensitivity Improvement of a 2D MEMS Thermal Wind Sensor for Low-Power Applications’, IEEE Sens. J., vol. 16, no. 11, pp. 4300-4308, Jun. 2016.

[18] J. J. Miau, T.S. Leu, J.M. Yu, J.K. Tu, C.T. Wang, V. Lebiga, D. Mironov, A. Park, V. Zinovyeg and K.M. Chung, 'Mems thermal film sensors for unsteady flow measurement', Sens. Actuators Phys., vol. 235, pp. 1-13, Nov. 2015.

[19] T. S. Leu, J. M. Yu, J. J. Miau, and S. J. Chen, 'MEMS flexible thermal flow sensors for measurement of unsteady flow above a pitching wind turbine blade', Exp. Therm. Fluid Sci., vol. 77, pp. 167-178, Oct. 2016.

[20] M. Shikida, K. Yoshikawa, S. Iwai and K. Sato, 'Flexible flow sensor for large-scale air-conditionning network systems', Sens. Actuators A Phys., vol. 188, pp. 2-8, Dec. 2012.

[21] I. Haneef, M. Umer, M. Mansoor, S. Akhtar, M.A. Rafiq, S.Z. Ali and F. Udrea, 'A tungsten based SOI CMOS MEMS wall shear stress sensor', in IEEE SENSORS 2014 Proceedings, 2014, pp. 1475-1478.

[22] R. Viard, A. Talbi, P. Pernod, A. Merlen, and V. Preobrazhensky, 'Miniaturised Sensor Comprising A Heating Element, And Associated Production Method', FR2977886 (A1) 2013-01-18 WO2013008203 (A2) 2013-01-17 WO2013008203 (A3) 2013-03-07 CN103717526 (A) 2014-04-09 EP2731908 (A2) 2014-05-21 US2014157887 (A1) 2014-06-12 EP2731908 (B1) 2015-09-09 DK2731908 (T3) 2015-12-21, 2013.

[23] R. Viard, A. Talbi, P. Pernod, A. Merlen, C. Frankiewicz, J-C. Gerbedoen and V. Preobrazhensky, 'A robust thermal microstructure for mass flow rate measurement in steady and unsteady flows', J. Micromechanics Microengineering, vol. 23, no. 6, p. 65016, Jun. 2013.

[24] C. Ghouila-Houri, J-C. Gerbedoen, J. Claudel, Q. Gallas, E.Garnier, A. Merlen, R. Viard, A. Talbi and P.Pernod, 'Wall Shear Stress and Flow Direction Thermal MEMS Sensor for Separation Detection and Flow Control Applications', Procedia Eng., vol. 168, pp. 774-777, 2016.

[25] C. Ghouila-Houri, J. Claudel, J-C. Gerbedoen, Q. Gallas, E.Garnier, A. Merlen, R. Viard, A. Talbi and P.Pernod, 'High temperature gradient micro-sensor for wall shear stress and flow direction measurements', Appl. Phys. Lett., vol. 109, no. 24, p. 241905, Dec. 2016.

[26] H. Nagib, K. A. Chauchan, and P. A. Monkewitz, 'Approach to an asymptotic state for zero pressure gradient turbulent boundary layers’, Philos. Trans. R. Soc., vol. 365, pp. 755-770, 2007. 